\title{
Usos e cobertura da terra e a sua relação com a naturalidade de paisagens culturais: o caso de Sorocaba (SP)
}

\author{
Land cover and its relation to cultural landscapes naturalness: the case \\ of Sorocaba (SP)
}

\author{
Fabio Leandro da Silva'(1), Welber Senteio Smith"1(1), Marcela \\ Bianchessi da Cunha-Santino'(i), Irineu Bianchini Júnior ${ }^{(1)}$ \\ 'Universidade Federal de São Carlos, São Carlos, SP, Brasil \\ "Universidade Paulista, Sorocaba, SP, Brasil
}

\begin{abstract}
RESUMO
As paisagens culturais consistem em um elemento resultante da conversão de componentes naturais em outros usos da terra, processo que acarreta na perda de naturalidade das paisagens e interfere na provisão de serviços ecossistêmicos. Nesse sentido, a análise dos padrões de mudanças do uso da terra e avaliação da naturalidade fornecem bases para a compreensão dos problemas ambientais e da interferência humana nos sistemas naturais. Frente ao exposto, o presente trabalho buscou verificar às mudanças de uso e cobertura da terra no município de Sorocaba (SP) entre 2007 e 2017, bem como a realização da análise da naturalidade através do Índice de Urbanidade (IB). Os resultados mostraram o predomínio de atividades do agronegócio e áreas urbanas. Reduções na classe agrícola e aumento da vegetação nativa foram constatadas. Em relação à Urbanidade, ocorreu o predomínio de categorias que indicam baixa naturalidade e alta interferência antrópica, mas com o incremento da vegetação nativa, ocorreu um aumento das áreas com alta e média naturalidade. O IB possibilitou verificar a relação dos usos da terra e naturalidade em uma paisagem cultural e apontou elementos que podem ser considerados no planejamento.
\end{abstract}

Palavras-chave: Índice de Urbanidade; Município; Geotecnologias

\section{ABSTRACT}

The cultural landscapes consist in an element resultant from natural components conversion in other land use, process that implies in naturalness landscape loss and interferes in the ecosystem services provision. In this sense, the land use patter analysis and naturalness evaluation provide base to environmental problems comprehension and the human interference on natural systems. Front of this, the present work aimed to verify changes in the land use of Sorocaba (SP) municipality between 2007 and 2017, as well as the analysis of naturalness employing the Urbanity Index (IB). The results showed the predominance of 
agribusiness activities and urban areas. Reductions in agricultural class and increase of native vegetation were constated. In relation to Urbanity, was verified the predominance of categories that indicates low naturalness and a high anthropic interference, but with the native vegetation increase, occurred an expansion of high and medium naturalness areas. The IB allowed to verify the relation of land use and naturalness in a cultural landscape and pointed elements that should be considered in the planning.

Keywords: Urbanity Index; Municipality; Geotechnologies

\section{INTRODUÇÃO}

Paisagens culturais podem ser compreendidas como um elemento dotado de valores ecológicos e econômico, resultante das mudanças de uso e cobertura da terra (FUSHITA \& SANTOS, 2015). Todavia, as alterações decorrentes das mudanças dos usos da terra exercem forte influência nos ecossistemas naturais e ocasionam a perda de naturalidade da paisagem (FERREIRA et al., 2018). Dentre as principais implicações, merece destaque a interferência na provisão de serviços ecossistêmicos, principalmente os serviços de suporte, base de todos os demais (MEA, 2005).

Desta forma, o entendimento dos padrões de mudanças do uso e ocupação da terra pode ser de grande auxílio para a compreensão do grau de modificação da paisagem pelas atividades humanas e permite a constatação de variações em sua naturalidade. As geotecnologias consistem em uma ferramenta que possibilitam a realização dessas análises, visto a obtenção de informações dos usos e cobertura da terra mediante o emprego de imagens de satélite e a possibilidade de análises temporais (NICOLAU et al., 2018), além da utilização de modelagens espaciais e verificação da implicação dos padrões de uso.

Sendo assim, a realização de estudos que forneçam base para o entendimento da naturalidade em escalas como o município, possibilitam o levantamento dos possíveis problemas associados e fornecem auxílio para a identificação das principais implicações das ações humanas nos sistemas naturais, além de apontar medidas que possam potencializar a naturalidade (SILVA et al., 2018). A promoção de estratégias conservacionistas e a elaboração de medidas gerenciais são possíveis através da verificação dos usos e cobertura da terra, situação que possibilita a verificação do atual estado das paisagens (WALZ \& STEIN, 2014) 
Diante do predomínio de um planejamento incipiente da paisagem no Brasil e a falta de integração do desenvolvimento das atividades humanas com a conservação ambiental (SILVA et al., 2017), se torna preciso a adoção de meios que forneçam um diagnóstico das principais mudanças e favoreçam a verificação da condição dos elementos naturais na paisagem.

Frente ao exposto, o presente trabalho buscou verificar os padrões de uso e cobertura da terra de uma paisagem cultural e o reflexo das alterações de sua naturalidade, por meio do Índice de Urbanidade.

\section{MATERIAIS E MÉTODOS}

\section{1 Área de Estudo}

Sorocaba é um município brasileiro localizado no interior do Estado de São Paulo (Figura 1), a cerca de $100 \mathrm{~km}$ da capital. O referido município faz parte da região metropolitana de Sorocaba e está inserido entre as coordenadas geográficas $47^{\circ} 34^{\prime} 12,000^{\prime \prime}$ W/ $23^{\circ} 21^{\prime} 3,600^{\prime \prime} \mathrm{S}$ e $47^{\circ} 18^{\prime} 10,800^{\prime \prime}$ W/ $23^{\circ} 35^{\prime} 20,058^{\prime \prime}$ S. Os municípios Alumínio, Araçoiaba da Serra, Iperó, Porto Feliz, Itu, Mairinque, Salto de Pirapora e Votorantim fazem divisa com Sorocaba.

De acordo com projeções demográficas realizadas pelo Portal de Estatísticas do Estado de São Paulo, para o ano de 2019, a população sorocabana é composta por 651.434 habitantes (SEADE, 2019). A economia do município é baseada principalmente nas atividades industriais e prestação de serviços, além do desenvolvimento de atividades relacionadas com o agronegócio (IBGE, 2010). O município de Sorocaba está inserido na Unidade de Gerenciamento de Recursos Hídricos Sorocaba-Médio Tietê. O clima da região é classificado como subtropical de altitude, caracterizada por uma estação chuvosa e outra seca bem definidas ao longo do ano (CLIMATE-DATA, 2019).

Figura 1 - Localização geográfica do município de Sorocaba. 


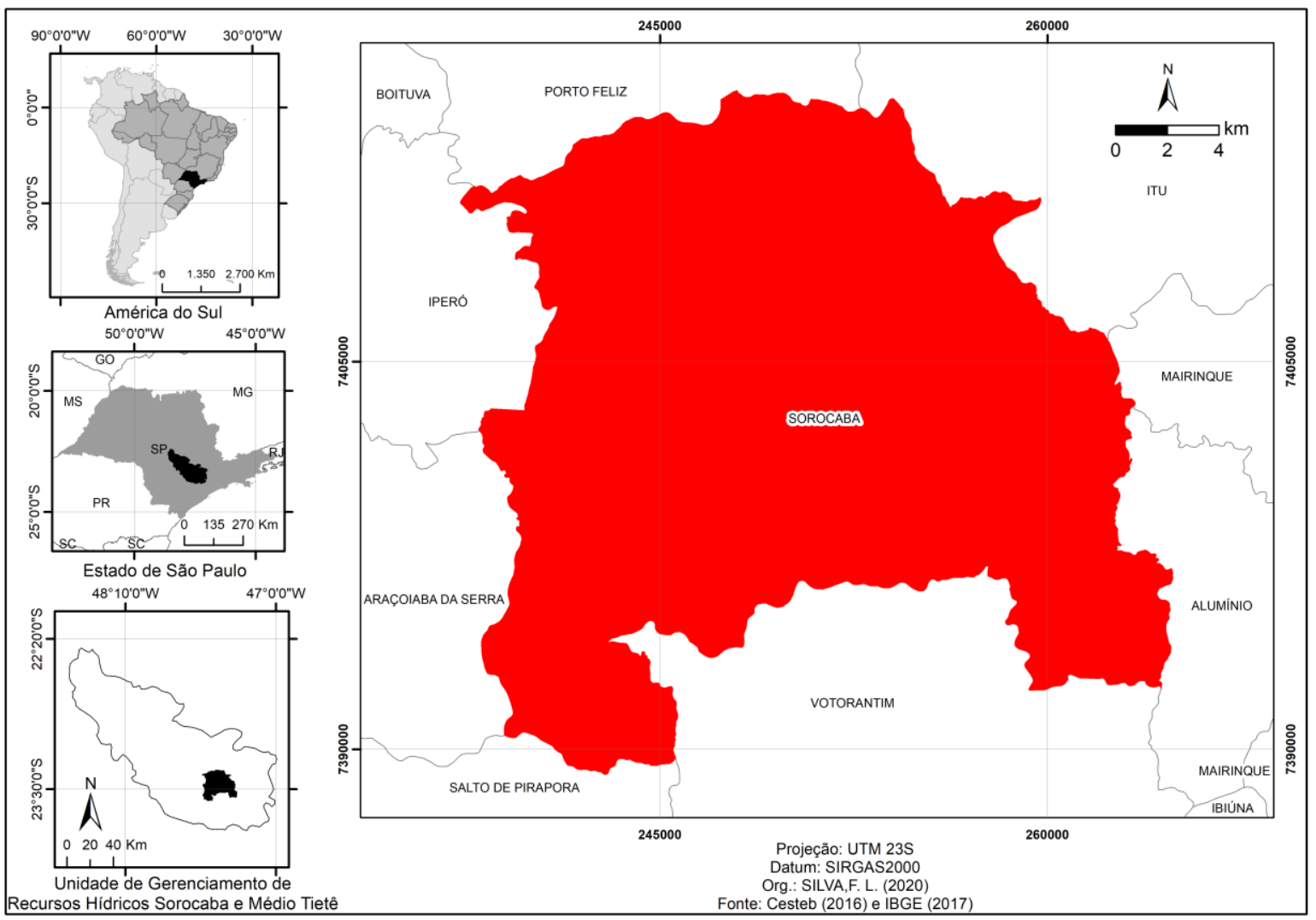

\subsection{Procedimentos metodológicos}

Os padrões de uso e cobertura da terra para o município de Sorocaba foram elaborados "on screen digitizing". Para o ano de 2007, foi realizada a composição multiespectral (5R4G3B) de imagens Landsat $5\left({ }^{\mathrm{TM}}\right)$ (órbita: 220/ ponto: 76) de 20 de junho de 2007, fornecidas pelo Instituto Nacional de Pesquisas Espaciais (INPE). Já para o ano de 2017, também foi realizada a composição multiespectral (6R5G4B) de imagens Landsat 8 (OLI) (órbita: 220/ ponto: 76), datada de 15 de junho de 2017 e disponibilizadas pelo Serviço Geológico dos Estados Unidos (USGS). A elaboração dos planos de informação ocorreu no software ArcGIS10.2. Para tanto, a resolução utilizada foi de 30 metros. O sistema de projeção adotado foi a Universal Transversa de Mercator (UTM) - Fuso 23 Sul, Datum SIRGAS2000.

Através do tom e textura, a classificação dos usos e ocupação da terra foi realizada. Buscando a obtenção do diagnóstico da naturalidade, o nível hierárquico adotado foi a classificação mediante classes, situação que forneceu o detalhamento necessário para a 
condução da análise, conforme sugerido pelo Manual de Uso da Terra do Instituto Brasileiro de Estatística e Geografia (IBGE, 2013).

A análise de urbanidade foi obtida por meio da aplicação do índice de Urbanidade (IB), criado por O’Neil et al. (1988). Tal índice se baseia na aplicação da lógica fuzzy linear $[y=f(x)]$, cuja escala possui uma variação de 0 a 1 (SILVA et al., 2017). Sendo assim, quando o IB é igual a 1, é constatado o grau máximo de naturalidade da paisagem e os sistemas estão submetidos a baixa interferência antropogênica. Por outro lado, quando o valor de IB é igual a 0, é constatada uma situação uma naturalidade mínima da paisagem e os sistemas estão alterados e submetidos a uma forte pressão humana.

Sendo assim, a verificação do grau e intensidade de domínio e alteração das paisagens pelo ser humano é definido através da seguinte equação 1 (WRBKA et al., 2004):

$$
I B=\log _{10}[A+U /(F+W)]
$$
Em que:
U: corresponde a extensão da área urbana,
A: corresponde a extensão da área agrícola,
F: corresponde a extensão de área de vegetação natural, e
W: corresponde à extensão dos corpos d'água e áreas alagáveis.

\section{RESULTADOS E DISCUSSÃO}

Ao realizar a análise espaço temporal do município de Sorocaba, entre os anos de 2007 e 2017, foi possível identificar algumas alterações nos usos e cobertura da terra. Quatro classes de uso e cobertura da terra foram identificadas: (i) agrícola, (ii) água, (iii) natural e (iv) urbano (Figura 2).

Figura 2 - Usos e cobertura da terra identificados para Sorocaba entre 2007 e 2017 


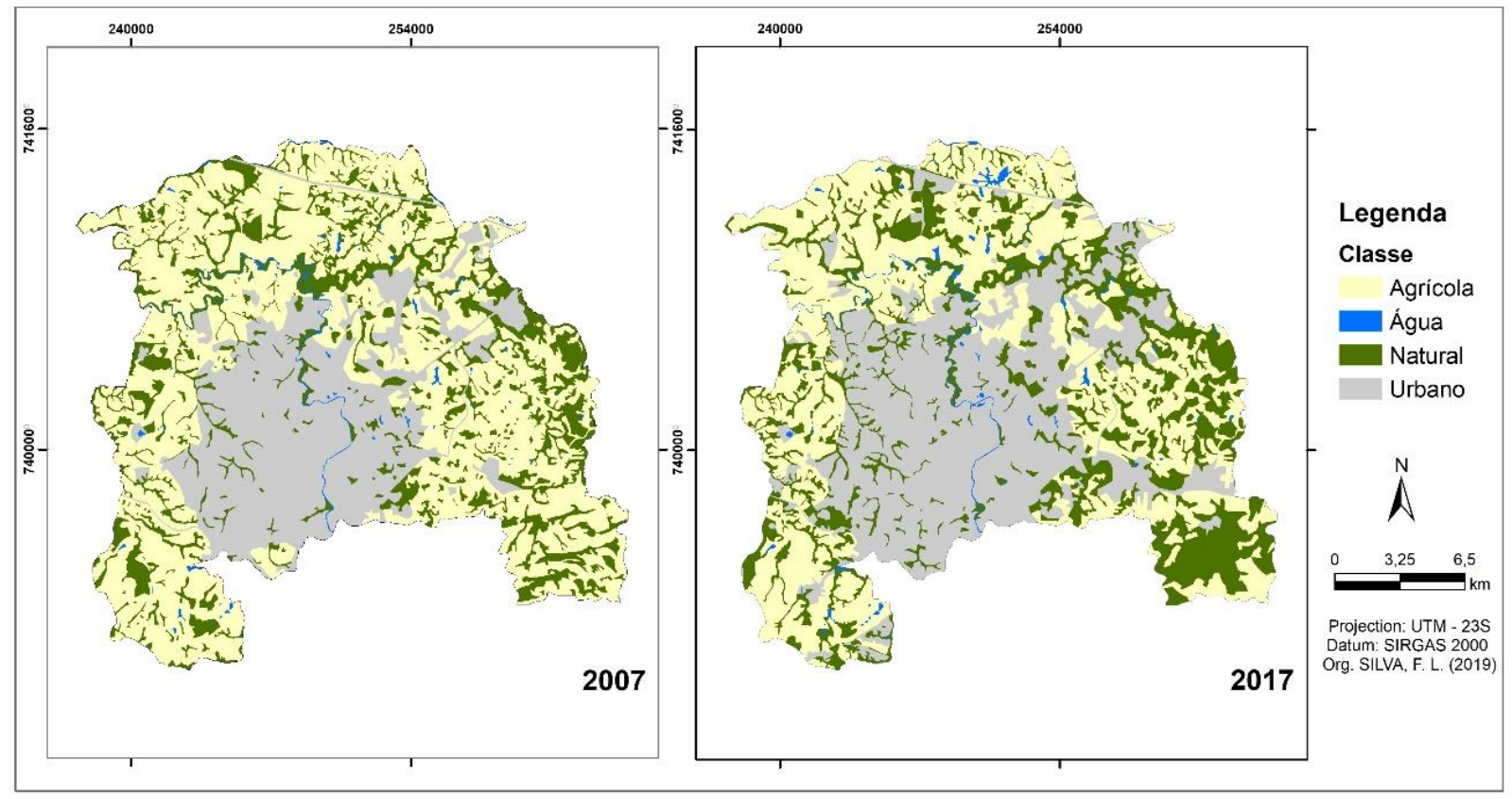

A classe agrícola englobou todas as atividades identificadas e relacionadas com o agronegócio, dentre as principais representantes no município, merecem destaque: cana-deaçúcar, pastagens, silvicultura e solo exposto. Por sua vez, a classe água possui relação com as áreas úmidas, com as represas e/ou reservatórios. A classe natural é composta por floresta semidecídua, mata atlântica e pelas diferentes fisionomias de cerrado existentes na área de estudo, além de comtemplar as áreas de preservação permanente e reservas legais. Por fim, a classe 'urbano' compreende as superfícies impermeabilizadas, adensamentos urbanos e áreas de mineração.

Observando a Figura 2, foi possível verificar o predomínio da classe agrícola no município de Sorocaba. Tal situação pode estar associada diretamente com os diversos ciclos econômicos vivenciados pelo município nos últimos séculos (SMITH et al., 2018). Destaca-se que, a classe agrícola pode ser considerada um dos principais fatores de alteração da paisagem de Sorocaba, seguida pelo processo de urbanização. Na sequência, a categoria 'urbano' ocupa uma grande parcela da área de estudo, um possível reflexo do grande contingente populacional ali existente. Natural e água representam as categorias que menos ocupam área na paisagem. Os padrões de uso e cobertura da terra encontrados são similares aos constatados por Silva (2010) durante uma análise entre os anos de 1988 e 2003.

Os dados representados na Tabela 1 demonstram variações no uso e cobertura da terra de Sorocaba ao longo de uma década. Com exceção da classe agrícola, as demais classes 
demonstraram ganho em área. É possível verificar um grande crescimento das áreas urbanizas e um pequeno incremento das áreas de vegetação nativa, situação possivelmente atrelada com a redução das áreas destinadas ao desenvolvimento do agronegócio. Os ambientes aquáticos apresentaram um ligeiro aumento, situação possivelmente associada com o regime de pluviosidade e a melhor delimitação das áreas úmidas. A variação positiva observada para a classe 'urbano' e natural possuem relação com a forte os eventos relacionados ao processo de urbanização e industrialização, além da existência de parâmetros florestais mais restritivos no que se remete aos federais, elemento que favorece a proteção e manutenção da vegetação nativa existente (MANFREDINI, 2015; CORRÊA; TONELLO; FRANCO, 2016) no território.

Tabela 1 - Classes de usos e cobertura da terra para o município de Sorocaba

\begin{tabular}{l|c|c|c|c|c}
\hline \multicolumn{1}{c|}{ Classes } & \multicolumn{2}{|c|}{$\mathbf{2 0 0 7}$} & \multicolumn{2}{c|}{$\mathbf{2 0 1 7}$} & Variação \\
\hline & Área (ha) & $(\%)$ & Área (ha) & $(\%)$ & $(\%)$ \\
\hline Agrícola & $24.237,12$ & 53,77 & $1.8453,04$ & 40,94 & $-23,86$ \\
\hline Água & 364,40 & 0,81 & 495,61 & 1,10 & 36,01 \\
\hline Natural & $8.513,34$ & 18,89 & $10.592,70$ & 23,50 & 24,42 \\
\hline Urbano & $11.956,84$ & 26,53 & $15.530,37$ & 34,46 & 29,89 \\
\hline Total & $45.071,71$ & 100 & $45.071,71$ & 100 & - \\
\hline
\end{tabular}

Em relação ao IB, cinco classes de naturalidade foram identificadas na área de estudo, que variam de classes que indicam uma grande influência antrópica (1) a classes que indicam maior grau de naturalidade e baixa interferência humana (5). Conforme a Figura 3, no município de Sorocaba, ocorre o predomínio de intervalos que refletem um menor nível de naturalidade da paisagem em ambos os anos considerados na análise (classes 1 a 3). A situação é um indicativo da forte influência das atividades humanas nos elementos naturais da paisagem, além de um elevado grau de modificação. Se tratando das áreas que possuem uma alta naturalidade, elas ocupam uma área pequena e distribuem-se por toda a área do município, são representadas principalmente pela vegetação nativa na região sudoeste.

Ficou evidente que as áreas enquadradas como fortemente modificadas se localizam em todo o território, porém a sua maior concentração ocorre na porção central de Sorocaba. Tais áreas são compostas principalmente pelas áreas urbanizadas e áreas agrícolas do município, situação que pode ser constatada com base na carta temática de usos e cobertura da terra. As regiões caracterizadas por graus intermediários de naturalidade e menores níveis 
de degradação estão associadas com fragmentos de vegetação e maior conectividade da paisagem.

Figura 3 - Representação espacial do IB para o município de Sorocaba

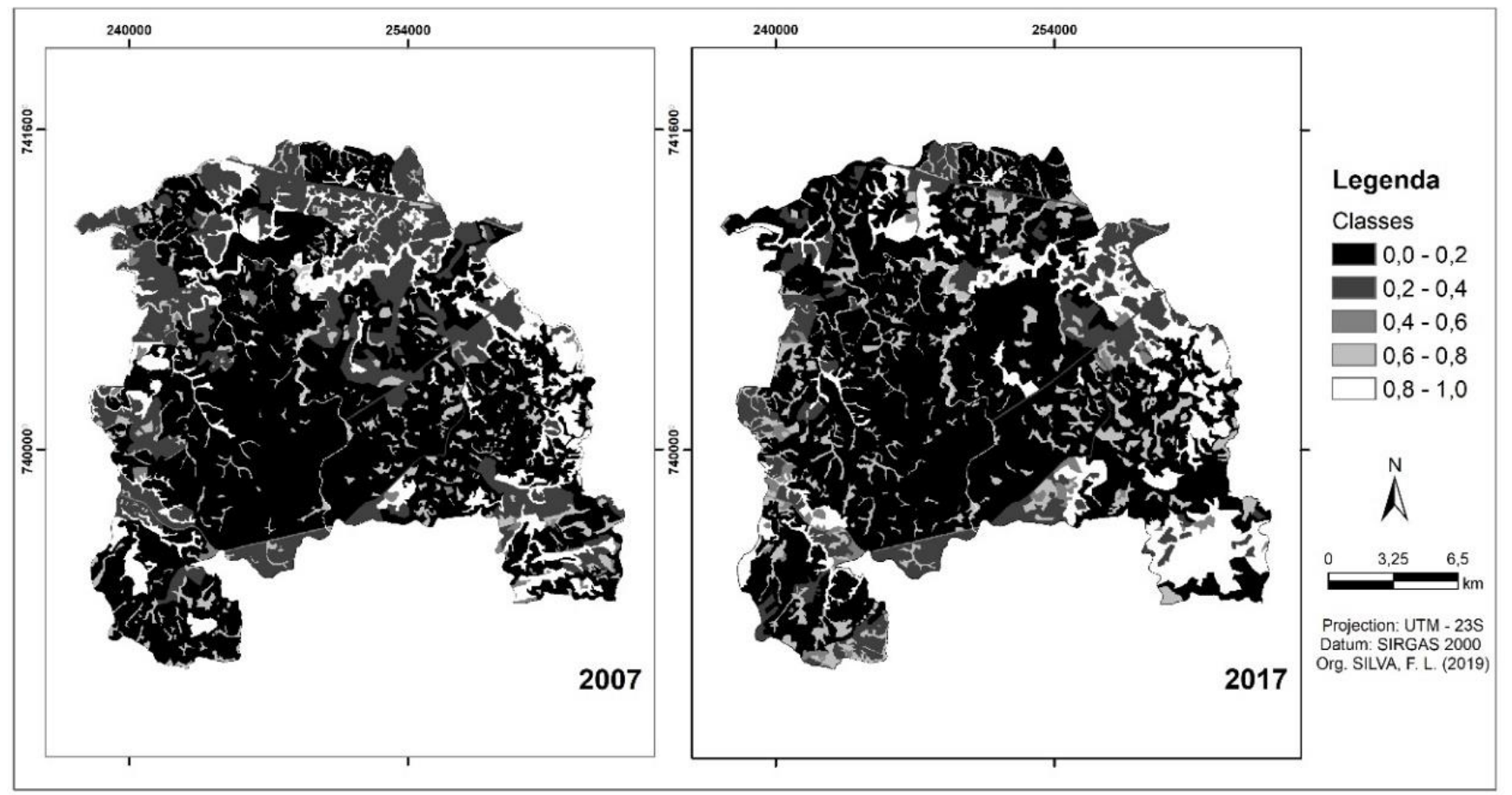

Variações do IB entre os anos de 2007 e 2017 foram constatados (Tabela 2). Mais de $79 \%$ das áreas existentes apresentaram um grau mínimo de naturalidade (classes 1 e 2) em 2007, todavia, uma grande redução dessas áreas ocorreu durante o ano de 2017. As áreas enquadradas com um grau intermediário de naturalidade e interferência humana (classe 3) demonstraram um elevado crescimento durante uma década, passaram a ocupar mais de metade do município de Sorocaba. Já as áreas que indicam maior naturalidade da paisagem (classes 4 e 5) apresentaram uma pequena variação positiva entre os anos avaliados, sendo que o menor ganho de área ocorreu na categoria que indica um menor grau de interferência antrópica e maior naturalidade.

A melhoria da naturalidade da paisagem constatada para o município de Sorocaba possivelmente se relaciona com o processo de recuperação das áreas degradadas e a adoção de uma agenda ambiental por parte do poder público, fatores que contribuíram efetivamente para a realização de plantios, recuperação das áreas legalmente protegidas e criação de zonas com restrição à ocupação (SMITH; MOTA JR; CASTELLARI, 2016). 
Tabela 2 - IB do município de Sorocaba para os anos de 2007 e 2017

\begin{tabular}{l|c|c|c|c|c|c}
\hline Urbanidade & & \multicolumn{2}{|c|}{$\mathbf{2 0 0 7}$} & \multicolumn{2}{c|}{$\mathbf{2 0 1 7}$} & Variação \\
\hline Classe & Intervalo & Área (ha) & $(\%)$ & Área (ha) & $(\%)$ & $(\%)$ \\
\hline 1 & $0,0-0,2$ & $25.851,00$ & 57,36 & $1.043,97$ & 2,32 & $-95,96$ \\
\hline 2 & $0,2-0,4$ & $9.791,00$ & 21,72 & $4.860,80$ & 10,78 & $-50,35$ \\
\hline 3 & $0,4-0,6$ & 590,00 & 1,31 & $27.555,45$ & 61,14 & $4.570,41$ \\
\hline 4 & $0,6-0,8$ & $3.213,00$ & 7,13 & $5.449,81$ & 12,09 & 69,62 \\
\hline 5 & $0,8-1,0$ & $5.626,71$ & 12,48 & $6.161,71$ & 13,67 & 9,51 \\
\hline Total & 100 & $45.071,71$ & 100 & $45.071,71$ & 100 \\
\hline
\end{tabular}

Silva et al. (2018) o avaliarem a naturalidade da paisagem entre os anos de 2007 e 2017 no município de Luís Antônio, também inserido no interior de São Paulo, constataram o grande predomínio de categorias que indicam baixa naturalidade da paisagem e uma grande interferência humana, situação que associaram diretamente com a urbanização e o agronegócio. Ao avaliarem outro município paulista, Fushita et al. (2016) encontraram padrões similares durante a avaliação conduzida entre os anos de 1989 e 2014 para o município de São Carlos. Os autores verificaram uma redução nas áreas agrícolas e aumento das áreas urbanas e de vegetação nativa, bem como verificaram o predomínio de áreas com baixo grau de naturalidade e um aumento nas áreas que possuem uma alta naturalidade (classe 5), situação também verificada no presente estudo.

Apesar da melhoria das condições de interferência humana e naturalidade da paisagem em Sorocaba, o desenvolvimento intensivo das atividades humanas tem contribuído para a degradação ambiental e desregulação dos ecossistemas naturais. A situação de degradação da paisagem observada, aliado à forte interferência antropogênica, contribuem de maneira efetiva para a perda dos serviços ecossistêmicos prestados (SILVA et al., 2017). Nesse sentido, é preciso a adoção de medidas que propiciem a continuidade da manutenção das áreas naturais e dos ambientes aquáticos, situação que favorece a manutenção do bem-estar da população local.

O aumento da naturalidade da paisagem contribui para a manutenção da autorregulação dos elementos na paisagem e promove melhorias na qualidade de vida da população (NUCCl; BELEM; KROKER, 2016). A antropização da paisagem ocorre em função do desenvolvimento econômico e industrialização, tais fatores resultam em uma série de alterações no funcionamento e metabolismo dos ecossistemas (SILVA et al., 2020). Ademais, a deterioração da vegetação nativa implica diretamente na provisão de serviços 
ecossistêmicos, deste modo, a manutenção dos ecossistemas naturais é indispensável para o planejamento e condução de um desenvolvimento mais sustentável (OLIVEIRA-ANDREOLI, 2019). Sendo assim, o diagnóstico realizado para o município de Sorocaba (SP) pode contribuir para a melhoria da naturalidade, trazendo contribuições para o planejamento.

\section{CONCLUSÕES}

O Índice de Urbanidade consistiu em um ótimo indicador para a verificação da naturalidade de paisagens culturais, considerando uma variação temporal. Salienta-se que, tal índice foi capaz de demonstrar as relações existentes entre usos e cobertura da terra e a naturalidade da paisagem. O município de Sorocaba (SP) apresentou, durante um intervalo de dez anos, o predomínio de classes que indicam um baixo grau de naturalidade da paisagem. Foi possível constatar que, o desenvolvimento das atividades relacionadas com o agronegócio e as áreas urbanizadas são os principais elementos responsáveis por exercerem pressões nos ecossistemas naturais. Tais classes de uso e cobertura da terra ocupam a maior parcela da paisagem analisada, juntas ocupam mais de $60 \%$ do território. A classe correspondente por indicar maior naturalidade $(0,8-1,0)$ sofreu um pequeno aumento durante o recorte temporal, situação propiciada pelo incremento observado na vegetação nativa, elemento que impede o agravamento dos impactos ambientais decorrentes das atividades antrópicas. Destaca-se que, a recuperação da vegetação possibilitou uma redução da classe que indica baixo grau de naturalidade e um aumento na categoria intermediária de naturalidade. Apesar da melhoria observada, é necessário a continuidade de medidas que promovam o aumento da conectividade entre os fragmentos vegetais remanescentes e a manutenção dos elementos naturais existentes, situação que pode ser favorecida através do planejamento ambiental. O presente estudo fornece bases para a realização de um planejamento da área, bem como possibilita a compreensão da problemática existente em paisagens culturais. Destaca-se que, a manutenção da naturalidade da paisagem é essencial para a continuidade da provisão dos serviços ecossistêmicos para a sociedade.

\section{AGRADECIMENTOS}


Os autores agradecem o suporte financeiro fornecido pelo Conselho Nacional de Pesquisa e Desenvolvimento Tecnológico - CNPq (Processos: 830728/1999-6 e 158927/2018-4).

\section{REFERÊNCIAS}

CLIMATE-DATA [Internet]. Clima Sorocaba [cited 2019 abr 30]. Available from: https://pt.climatedata.org/america-do-sul/brasil/sao-paulo/sorocaba-756/. Access in: 30 Abr 2019.

CORRÊA, C. J. P.; TONELLO, K. C.; FRANCO, F. S. Análise hidroambiental da microbacia do PirajibuMirim, Sorocaba, SP, Brasil. Revista Ambiente \& Água, v. 11, n. 4, p. 943-953, 2016.

FERREIRA, C. S.; SILVA, F. L.; MOITAS, M. L.; FUSHITA, A. T.; BIANCHINI JÚNIOR, I.; CUNHA-SANTINO, M. B. River Monjolinho Watershed: water quality, sediment and Hemeroby Index. Ambiência, $v$. 14, n. 3, p. 522-538, 2018.

FUSHITA, A. T.; SANTOS, J. E. Socio-Economic Metabolism and Sustainability at a Watershed. Open Journal of Applied Sciences, v. 5, p. 678-687, 2015.

FUSHITA, A. T.; SANTOS, J. E.; SOUZA, I. M. M.; ROMANINI, E. R.; COSTA, R. T. Landscape Structural Indicators as a Tool to Assess Land Use Changes in Planning for Sub-Basin Sustainability (Southeastern Brazil). Journal of Water Resources and Protection, v. 8, n. 4, p. 482-492, 2016.

INSTITUTO BRASILEIRO DE GEOGRAFIA E ESTATÍSTICA - IBGE [Internet]. Cidades [cited 2019 abr 30]. Available from: https://cidades.ibge.gov.br/brasil/sp/sorocaba/panorama. Access in: 30 Abr 2019.

INSTITUTO BRASILEIRO DE GEOGRAFIA E ESTATÍSTICA - IBGE. Manual Técnico de Uso da Terra [Internet]. 3. ed. Rio de Janeiro (Brasil): IBGE, 2013 [cited 2020 set 18]. Available from: https://biblioteca.ibge.gov.br/visualizacao/livros/liv81615.pdf. Access in: 18 Set 2020.

MANFREDINI, F. N. A história ambiental de Sorocaba. 1. ed. Sorocaba: Unesp, 2015, 180 p.

MILLENNIUM ECOSYSTEM ASSESSMENT - MEA [Internet]. Ecosystems and Human Wellbeing: Synthesis [cited 2019 abr 30]. English. Available from:

https://www.millenniumassessment.org/documents/document.356.aspx.pdf .Access in: $30 \mathrm{Abr}$ 2019.

NICOLAU, R. C. P.; KAWAKUBO, F. K.; POLO, R. L.; MINCATO, R. L. Implicações ambientais do novo código florestal brasileiro. Revista Brasileira de Ciências Ambientais, v. 48, p. 38-51, 2018.

NUCCI, J. C.; BELEM, A. L. G.; KROKER, R. Evolução da paisagem do bairro Santa Felicidade com base no conceito de hemerobia. Revista Do Departamento De Geografia, v. 31, p. 58-71, 2016.

O'NEILL RV, et al. Indices of landscape pattern. Landscape Ecology, v. 1, n. 3, p. 153-162, 1988.

OLIVEIRA-ANDREOLI, E. Z.; SILVA, F. L.; AGUILAR-LÓPEZ, F. M.; MACHADO, R.; TEODORO, C. C.; BIANCHINI JR., I.; CUNHA-SANTINO, M. B.; FUSHITA, A. T. Importância do planejamento regional 
para a manutenção dos usos múltiplos da água em bacias hidrográficas. Revista Brasileira de Ciências Ambientais, n. 52, p. 16 - 27, 2019.

PORTAL DE ESTATÍSTICAS DO ESTADO DE SÃO PAULO - SEADE [Internet]. Sistema Seade de Projeções Populacionais [cited 2019 abr 30]. Available from:

https://produtos.seade.gov.br/produtos/projpop/index.php. Access in: 30 Abr 2019.

SILVA, A. M. Land cover change and environmental quality assessment using GIS techniques - a case study in Brazilian Southeastern region for the period 1988 - 2003. Revista Ambiente \& Água, v. 5, n. 2, p. 40-50, 2010.

SIlVA, F. L.; OliVeIRA, E. Z.; PICHARILlO, C.; RUGGIERO, M. H.; COSTA, C. W.; MOSCHINI, L. E. Naturalidade da paisagem verificada por meio de indicadores ambientais: manancial do Rio Monjolinho, São Carlos-SP. Revista Brasileira de Geografia Física, v. 10, n. 3, p. 970-980, 2017.

SILVA, F. L.; STEFANI, M. S.; SMITH, W. S.; SCHIAVONE, D. C.; CUNHA-SANTINO, M. B.; BIANCHINI JR., I. An applied ecological approach for the assessment of anthropogenic disturbances in urban wetlands and the contributer river. Ecological Complexity, v. 43, p. 1 - 12, 2020.

SILVA, K. F.; DORICI, M.; ALMEIDA, D.; MORALES, L. S.; MOSCHINI, L. E. Naturalidade da paisagem do município de Luís Antônio, São Paulo. Ciência e Natura, v. 40, p. [S.I.], 2018.

SMITH, W. S.; MOTA, JR. V. D.; CASTELLARIA, R. R. O papel do município na conservação da biodiversidade. Rev. Biologia Neotropica. v. 13, n. 2, p. 285-299, 2016.

SMITH, W. S.; SILVA, F. L.; AMORIM, S. R.; SEVERINO, M. S. Urban biodiversity: how the city can do its management?. Biodiversity International Journal, v. 2, n. 3, p. 272-277, 2018.

WALZ, U.; STEIN, C. Indicators of hemeroby for the monitoring of landscapes in Germany. Journal for Nature Conservation. v. 22, p. 279-289, 2014.

WRBKA, T.; ERB, K.; SCHULZ, N. B.; PETERSEIL, J.; HAHN, C.; HABERL, H. Linking pattern and process in cultural landscapes. An empirical study based on spatially explicit indicators. Land Use Policy, v. 21, n. 3, p. 289-306, 2004.

\section{CONTRIBUIÇÕES DE AUTORIA}

\section{1 - Fabio Leandro da Silva}

Doutorando em Ecologia e Recursos Naturais na Universidade Federal de São Carlos. http://orcid.org/0000-0001-6002-9030 - fabioleandro@alumni.usp.br

Contribuição: Conceituação, análise formal, investigação, métodos, validação, visualização, redação - rascunho original

\section{2 - Welber Senteio Smith}

Docente da Universidade Paulista (campus Sorocaba). Docente do Programa de PósGraduação em Ciências da Engenharia Ambiental da Universidade de São Paulo e do 
Programa de Pós-Graduação em Aquicultura e Pesca da Agência Paulista de Tecnologia dos Agronegócios - Instituto de Pesca.

http://orcid.org/0000-0001-9803-7394 - welber_smith@uol.com.br

Contribuição: Escrita - Revisão e Edição

\section{3 - Marcela Bianchessi da Cunha-Santino}

Docente do Departamento de Hidrobiologia, Universidade Federal de São Carlos. Docente do Programa de Pós-Graduação em Ecologia e Recursos Naturais da Universidade Federal de São Carlos.

http://orcid.org/0000-0002-9121-3794 - cunha_santino@ufscar.br Contribuição: Escrita - Revisão e Edição

\section{4 - Irineu Bianchini Júnior}

Docente do Departamento de Hidrobiologia, Universidade Federal de São Carlos. Docente do Programa de Pós-Graduação em Ecologia e Recursos Naturais da Universidade Federal de São Carlos.

http://orcid.org/0000-0002-9121-3794 - irineu@ufscar.br

Contribuição: Escrita - Revisão e Edição

\section{COMO CITAR ESTE ARTIGO}

SILVA, F. L.; SMITH, W.S.; CUNHA-SANTINO, M. B.; BIANCHINI JÚNIOR., I. Usos e cobertura da terra e a sua relação com a naturalidade de paisagens culturais: o caso de Sorocaba (SP). Ciência e Natura, Santa Maria, v. 43, e35, p. 1-13, 2021. Disponível em: https://doi.org/10.5902/2179460X38708. Acesso em: dia, mês (abreviado), ano. 